\title{
Innovation Entanglement at Three South African Tech Hubs
}

\author{
Lucienne Abrahams \\ Director, LINK Centre, University of the Witwatersrand (Wits), Johannesburg; and \\ Researcher, Open African Innovation Research (Open AIR) \\ iD https://orcid.org/0000-0002-5219-8448
}

\begin{abstract}
This study explores innovation modalities at three South African tech hubs: Bandwidth Barn Khayelitsha and Workshop 17 in Cape Town, and the Tshimologong Digital Innovation Precinct in Johannesburg. The study finds that tech start-ups' ability to scale is generally enhanced by their participation in the hubs. Furthermore, it is found that scaling by start-ups, and by the tech hubs hosting them, is enhanced when they actively drive the terms of their "entanglement" with exogenous and endogenous factors and external entities - a conceptual framework first developed in an earlier study of university research linkages (Abrahams, 2016). This present study finds that innovation entanglement by the hubs and their start-ups allows them to work through the adversity and states of complexity prevalent in their innovation ecosystems.
\end{abstract}

\section{Keywords}

tech hubs, digital innovation, tech enablement, collaboration, knowledge creation, knowledge governance, complexity, innovation entanglement, South Africa

\section{Acknowledgements}

The research for this article was carried out as part of the Wits LINK Centre's participation in the Open African Innovation Research (Open AIR) network, in partnership with the University of Cape Town, the University of Johannesburg, Strathmore University in Nairobi, the Nigerian Institute of Advanced Legal Studies, and The American University in Cairo. The author acknowledges the support provided for this research by Open AIR, the Social Sciences and Humanities Research Council (SSHRC) of Canada, the International Development Research Centre (IDRC), and the UK Department for International Development (DFID). The views expressed in this work are those of the author and do not necessarily represent those of the research funders. The author also extends thanks for the contributions of all the research respondents, and for the contribution made by Wits LINK Centre Master's student Yolisa Kedama, who compiled information on all South African tech hubs in operation at the time of the research. The LINK Centre is amongst the founding institutions at one of the three hubs studied, the Tshimologong Digital Innovation Precinct.

DOI: https://doi.org/10.23962/10539/30358 


\section{Recommended citation}

Abrahams, L. (2020). Innovation entanglement at three South African tech hubs. The African Journal of Information and Communication (AJIC), 26, 1-29. https://doi.org/10.23962/10539/30358

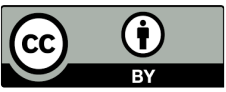

This article is licensed under a Creative Commons Attribution 4.0 International (CC BY 4.0) licence: https://creativecommons.org/licenses/by/4.0

\section{Introduction: The need to explore "entanglement" in tech hub innovation ecosystems}

Tech hubs can be seen as interacting ecosystems-or communities of researchers, software developers, digital makers, tech start-ups, small and micro enterprises (SMEs), and corporate clients and investors in innovation-brought together "to create the best conditions for long-term business success for all involved" (Zwegers \& Sassen, 2015). Tech hubs generally include learning, incubator, and accelerator facilities. They focus on a wide range of industries and sectors moving into digitalisation, hosting young entrepreneurs designing digital applications and content for agriculture (a local South African example is pest management in macadamia nut orchards), education (a local example is online learning for applications in dynamic software for secondary school mathematics teachers), energy, fashion, health, retail, and other sectors. Tech hubs are an interesting phenomenon on the African continent, particularly in Kenya, Nigeria, and South Africa which have many, as the hubs operate with limited resources and stand in stark contrast to the large global platform firms and content providers (e.g., Amazon, Facebook, Netflix) (Van der Aalst et al., 2019) and to the global-scale cloud service providers and systems integrators and aggregators (e.g., Microsoft Azure, Google, Oracle Cloud) (Holst, 2020).

The common feature across tech hubs is that they are collaborative working spaces and competence building-centres, using digital technology to incubate tech and business start-ups and/or to accelerate existing businesses. While broadband internet penetration is still relatively low on the African continent, the rapid growth in $\mathrm{Wi}$ Fi hotspots, smart phones, and laptop devices has advanced internet penetration and access, creating demand for digital applications (apps), software platforms, 3D-printing, data analytics, and digital solutions, ranging from digital health to smart homes and smart city solutions. Tech hubs have become spaces where young aspiring tech start-ups can access fast $\mathrm{Wi}-\mathrm{Fi}$, office space, and meeting space; receive training, coaching, and mentorship; engage in networking and building partnerships; and get assistance with start-up funding, venture capital funding, and other inputs. Most tech hubs in South Africa, as on the African continent in general, provide arenas for learning and practising software development and related skills, as well as the 
business and management skills required for tech start-ups to participate in the digital innovation ecosystem, and to advance their capacities, their creativity and their income. These tech start-ups are learning and actively producing in response to a demand for niche solutions and/or platform-based solutions.

\section{Research problem statement}

Extensive digitisation in the context of creating inclusive future cities (Banai, 2020), convergence innovation beyond digital automation (Lee \& Trimi, forthcoming 2021), and the COVID-19 digital surge illustrating socio-economic benefit and cyber-risk (De et al., 2020) should all focus our attention on tech hubs as particular institutional spaces for digital innovation. These developments indicate that it is relevant, in the pandemic period and beyond, to consider the evolutionary nature of tech hubs, as this could be a period of heightened integration with clients, cities, and communities to meet increasing demand, or a period of high risk of economic marginalisation. With respect to the complexity of addressing either of these challenges (meeting demand or potential marginalisation), tech hubs will need greater capacities and influencing factors than just their innovative or entrepreneurial capabilities. Clustering is one of the ways in which high-tech start-ups gain ground: Adler et al. (2019) analyse the macro-geographic spread of high-tech clusters across city-regions, as well as the micro-geographic organisation and the spatial division of labour at a neighbourhood level. Other important mechanisms include business model evolution and contextual ambidexterity (Balboni et al., 2019). However, there are yet other means that tech hubs use to evolve, where the key actors and institutions slowly succeed, despite the challenges of limited resources.

This study's research problem, investigated in the context of South Africa, engages with elements of "entanglement" by actors (tech start-ups created by innovator-entrepreneurs) and institutions (tech hubs that host start-ups) with influencing factors (resources, values and value) and entities in an innovation ecosystem. In South African innovation ecosystems characterised by limited resources and emerging values systems, entanglement can serve as a means to enhance the actors' and institutions' strategic positioning and hence their value-creation capability, both of which are necessary for progressing to scale. This study's exploration of innovation entanglement builds on previous research (Abrahams, 2016) that focused on research-oriented entanglement by South African universities.

In order to advance the strategic positioning and resilience of tech hubs in Africa, it is necessary to understand the approaches to scaling that are present in the strategies and activities of these tech hubs. This research problem was chosen because of its relevance to the frequent focus on scaling in existing tech innovation literature (Atiase et al., 2020; ElHoussamy et al., 2020; Kelly \& Firestone, 2016; Littlewood \& Kiyumbu, 2018; Nzomo et al., 2020; Open AIR, 2020), its relevance to the sustainability of tech hub communities and the start-up enterprises that make up these 
communities, and its relevance to the integration of tech hubs into broader digital innovation ecosystems. Three South African tech hubs, along with their resident start-ups, were selected for study.

\section{Context: Tech hubs operating under adverse conditions}

\section{Tech bubs in Africa}

Critical reviews of digital tech hubs in Africa (see Comins \& Kraemer-Mbula, 2016; De Beer et al., 2017; Desta, 2018; ElHoussamy et al., 2020; Friederici, 2019; Jiménez \& Zheng, 2017) are essential to promoting sustainability and long-term success, as they promote deep insight into real-world institutions and innovation challenges. In 2019, the GSMA Ecosystem Accelerator programme reported that there were 618 tech hubs active in Africa, a 40\% increase since 2018 (Giuliani \& Ajadi, 2019). Unlike that report's definition of tech hubs as including those that "only offer co-working facilities instead of specifically tech-focused support programmes or funding", this study considers tech hubs to include those that actively engage in the creation of digital applications and services, or actively engage in any form of additive manufacturing, or use digital tools and infrastructures for digitally supported entrepreneurship. The application and use of digital technologies in each of these forms can support small business start-ups, and cater for demand from medium to large businesses, public sector clients, and non-governmental clients.

The four African countries found by GSMA Ecosystem Accelerator to have the most hubs were Nigeria (85 hubs), South Africa (80), Egypt (56), and Kenya (48) (Giuliani \& Ajadi, 2019). For the purposes of this study, it is argued that tech hubs in Africa generally operate under adverse conditions, as their innovator-entrepreneur and start-up communities compete with large national and global firms for innovation resources (both financial and non-financial), operating in small corners of the markets for digital applications and services. This presents a major barrier to scaling up, as relevant to the tech start-ups, the tech-enabled businesses, and the tech hub itself.

\section{South African tech hubs}

The scope for this study of South African tech hubs was limited, selecting from among the hubs, incubators, and co-working spaces where digital innovation is the focus, or where digital technologies are used as an enabler of productive activity. At the time of the research, roughly 50 entities across four of South Africa's nine provinces met these criteria, the provinces being Gauteng, the Western Cape, KwaZulu-Natal and the Eastern Cape. An AfriLabs and Briter Bridges 2019 report documents 78 active tech hubs in South Africa (Giuliani et al., 2019, p. 6), with that report's definition of tech hubs including co-working spaces, incubators, accelerators, and hybrid innovation hubs. 
Both our data collection and the Giuliani et al. (2019) data confirm that the two largest concentrations of tech hubs in South Africa are in the Western Cape and Gauteng, which are home, respectively, to South Africa's second-largest and largest cities, Cape Town and Johannesburg. Accordingly, the three hubs identified for study (see "Constructivist research design" section below) were two hubs in greater Cape Town and one in Johannesburg.

\section{The concept of entanglement}

Briefly expressed, the initial concept of research entanglement refers to the positionings that actors and institutions adopt, within university research sub-systems characterised by adversity and increased complexity, in relation to ecosystem factors (resources, values, and value) and external entities within the same ecosystem. The actors and institutions tend to position themselves in a heightened state of interaction with the often-competing ecosystem factors (grounded in resources, values, and value) and with external entities, in order to gain advantage and overcome adversity within that ecosystem (Abrahams, 2016). The competing factors and external entities can either shape the evolution and hardiness of the actors and institutions, or see them fade from existence (Abrahams, 2016). In the present study, the innovation entanglement with competing ecosystem factors and with external entities was explored in respect of the positionings of tech start-ups (the actors) and the tech hubs (the institutions) hosting the start-ups.

\section{Constructivist research design}

This study used a constructivist research methodology, so as to allow for exploration of the application of the entanglement conceptual framework established via the grounded theory methodology in the earlier study (Abrahams, 2016). This study sought to obtain insights into entanglement modalities present in South African tech hub innovation ecosystems.

\section{Data collection}

Data collection was conducted at three tech hubs, selected due to the apparent differences in their features, in their locations within their cities, and in their phases of evolution: Bandwidth Barn Khayelitsha (Cape Town), Workshop 17 (Cape Town), and Tshimologong Digital Innovation Precinct (Johannesburg). The data collection process comprised: observation of business overview presentations from innovator-entrepreneurs at each of the hubs and meetings with hub community management, in order to inform the design of the interview protocol; desktop review of background data on tech hubs in South Africa; semi-structured interviews with 17 respondents at the three hubs; and a focus group at Bandwidth Barn Khayelitsha. The interview respondents - seven at Bandwidth Barn Khayelitsha, five at Workshop 17, and five at the Tshimologong Digital Innovation Precinct-were a mix of (1) hub community 
managers and (2) key informants resident in the hubs as innovator-entrepreneurs, establishing tech start-ups engaged in incubating or accelerating start-ups. The focus group at Bandwidth Barn Khayelitsha comprised six women engaged in micro-businesses. Ethical clearance for the research was obtained from the Human Research Ethics Committee Non-medical, University of the Witwatersrand, with Protocol Number H16/11/01.

\section{Data analysis}

The data analysis was qualitative, consisting of identifying the core recurrent themes in the transcripts of the 17 interviews and of the focus group discussion. In this article's reporting of the findings from the data, the respondent codes used are as follows:

- $\quad$ respondents BBK1 to BBK7 = the seven Bandwidth Barn Khayelitsha respondents;

- $\quad$ respondents W17.1 to W17.5 = the five Workshop 17 respondents;

- $\quad$ respondents T1 to T5 = the five Tshimologong Digital Innovation Precinct respondents; and

- BFG respondents = the Bandwidth Barn Khayelitsha focus group respondents.

\section{The three hubs studied}

As stated above, the three hubs selected for study-Bandwidth Barn Khayelitsha and Workshop 17 in Cape Town, and the Wits Tshimologong Digital Innovation Precinct in Johannesburg-were selected because of their apparent differences in terms of features, locations, and stages of evolution. At the same time, however, the hubs do have several commonalities. All three have attractive, high-ceilinged, multi-use, flexible-use spaces for co-working and events, including shared tables, discussion nooks, working areas with couches and tables, whiteboards, and cubby holes for storage; a staffed front desk; a coffee shop; a strong youth focus; and, very importantly, high speed $\mathrm{Wi}-\mathrm{Fi}$. All three cater, to varying degrees, for activities related to pre-incubation, to start-up incubation, and to business acceleration. For all three, these types of activities include regular events to engage the resident tech community in specially designed innovation learning, in broader digital knowledge content, and in engagements with potential business clients and small-scale investors.

\section{Bandwidth Barn Khayelitsha}

Bandwidth Barn Khayelitsha is a tech hub for entrepreneurs in all fields. It is located at Lookout Hill, a tourism centre overlooking Khayelitsha, with a view of the mountains and the sea, in a community with formal residential areas but with a preponderance of informal settlements. Khayelitsha, though part of greater Cape Town, is located far from the city's main productive and services sectors. The community experiences high levels of unemployment, food insecurity, infrastructure shortcomings, and extreme poverty. In this socio-economic context (Beyond our Borders, 2017), the Bandwidth Barn caters mainly for tech-enabled businesses and also for some tech 
start-ups. This tech hub was, at the time of the research, offering free space to its resident businesses and start-ups, and it planned to later move to a rental model. All the businesses and non-profit organisations (NPOs) operating from the tech hub at that time were incorporating tech usage in their operations, e.g., for registration of a company when it reaches the appropriate stage of business development, for digital marketing, and for doing background research for a business (respondent BBK7; $\mathrm{BFG}$ respondent). The Bandwidth Barn is open from 09h00 to $17 \mathrm{~h} 00$ on weekdays, with ad hoc events taking place outside of those hours as arranged, including some at weekends.

\section{Workshop 17}

Workshop 17 is specifically designed as an innovation space, with tech serving as an enabler of innovation and often also as a key feature of innovation. It is located in central Cape Town's Waterfront district, the city's top destination for local and international tourism, which has had more than 24 million visitors and has generated ZAR335billion (approx. USD20.6 billion ${ }^{1}$ ) in revenue since 1990 (V\&A Waterfront, 2020). Workshop 17's main hours of operation are $07 \mathrm{~h} 00$ to $19 \mathrm{~h} 00$ on weekdays, with community members able to use the venue after hours and with many events and tech talks taking place over weekends. Firms located at Workshop 17 at the time of the research were engaged in, inter alia, conceptual marketing, crowd-sourcing of data for clients, building data models, building financial technologies (fintech), managing events and event security, coding, creative design for digital branding and marketing for small businesses, apps design, platform design, and 3D-printing. Workshop 17 now has five locations in South Africa, but had only one at the time of data collection.

\section{Tshimologong Digital Innovation Precinct}

The Tshimologong Digital Innovation Precinct is, formally, an entity of the University of the Witwatersrand located in the Johannesburg inner city area of Braamfontein. The Precinct's environment is characterised by inner city businesses, historical buildings and railway yards, cultural precincts, proximity to two universities (Wits University and the University of Johannesburg), and a view of the Witwatersrand gold mine dumps (Trangoš, 2015). Braamfontein has a resident tertiary student population of around 6,700 (Gregory \& Rogerson, 2019), including students registered at Wits, the University of Johannesburg, and several technical and vocational training colleges located in and around Braamfontein. The tech hub operates within its own framework, but under the rules and procedures of the university. Tshimologong's operating hours are $07 \mathrm{~h} 00$ to $22 \mathrm{~h} 00$ weekdays, with ad hoc events and hackathons taking place after hours as arranged (including on weekends), including the Wits Fak'ugesi African digital creativity festival, which usually runs in September each year but went virtual during October to November 2020, as a result of the COVID-19 pandemic (Fak'ugesi, n.d.).

\footnotetext{
1 Calculated based on the ZAR: USD exchange rate on 25 October 2020.
} 


\section{Findings on hubs' and start-ups' innovation modalities}

The findings are presented here in the thematic categories that emerged most strongly from the interview and focus group data, as follows:

- hub provision of infrastructure and services;

- hub provision of networking opportunities;

- hub provision of opportunities for collaboration;

- hub and start-up approaches to knowledge governance; and

- hub and start-up approaches to local appropriateness.

\section{Hub provision of infrastructure and services}

One of the core themes present in the data is bub provision of infrastructure and services, i.e., provision of $\mathrm{Wi}-\mathrm{Fi}$ service, office space, meeting rooms, events spaces, pre-incubation support, incubation support, and in-hub acceleration support. The tech hubs provide access to an extensive range of tangible and intangible resources not otherwise available to young digital entrepreneurs or to tech and business start-ups.

Respondent W17.4 at Workshop 17 proposed several core requirements essential to hub success, including: location (e.g., proximity to transport nodes, availability of parking, being in a district that is neither plateauing nor declining in economic attractiveness); the physical space (e.g., heating, ventilation, air-conditioning, lighting, high ceilings, outside spaces); and human elements (well-trained, highly educated employees passionate about creating tech hub success). Respondent BBK7 at Bandwidth Barn Khayelitsha said the four key elements needed by a tech hub are: (1) ensuring a flow of skills into and among the tech start-ups; (2) providing an incubator service; (3) connecting start-ups to industry partners and to enterprise development opportunities; and (4) having some industry partners operating from the hub. According to Tshimologong respondents T4 and T5, a successful tech hub requires a specific resource environment, including the availability of: software systems, engineering resources, facilities for hosting the app or the platform, testing and stress-testing facilities, and funding to hire developers. At Tshimologong, some of these resources are brought and provided by the community members themselves (respondents T4, T5).

Respondent BBK2 spoke of being "here for the space", due to a lack of privacy at home and the need for a suitable environment to meet with clients. Respondent $\mathrm{BBK} 3$, whose business is focused on financial literacy training through online video tutorials in multiple local languages, said: "I really need access to internet because I always have to be online, [and it must be] fast enough."

Another necessary element commented on by respondents is flexibility of pricing. Tech hubs generally charge membership fees on a tiered basis, with the fee dependent on the space resources and the services they need to use. Respondent W17.1 favoured per-use pricing, e.g., a charge per hot desk, per-use, on the grounds that 
such pay-as-you-go models allow members to "spend less or spend more; that's what these environments give us [...]. Add on what you need as opposed to [a] pay-perresource-bundle.”

Although both Tshimologong and Workshop 17 offer access to their shared workspaces and services at prices substantially lower than prices in the commercial market, some respondents at these hubs voiced concern that the prices are still unaffordable for many individuals and enterprises that come from low-income communities. By way of demonstration, the current tiered scheme for Tshimologong has five price levels, ranging from ZAR1,500 [USD92,70] per month for full access, including mentorship and tech and business development Master classes; ZAR800 [USD49,42] per month for light access, excluding mentorship; ZAR120 [USD7,41] per day for "no frills" drop-in users; R300 [USD18,53] per month for student users; and ZAR150 [USD9,26] per month for virtual users (Tshimologong, 2020). Workshop 17 membership fees range between the $\mathrm{On}$ the Road membership, starting at ZAR1,100 [USD67,96] per month (60 hours per month, with additional costs for add-ons), and the Rooted membership, starting at ZAR3,318 [USD204,99] per month (access to all five locations plus add-ons), with all memberships including private access to the Workshop 17 community and events (Workshop 17, 2020).

According to respondents, tech hubs need to offer both low overheads and attractive social environments, with the key words used being "young", "creative", "hip", and "non-traditional". Respondents from enterprises making use of Bandwidth Barn Khayelitsha and Workshop 17 spoke of the attractiveness of being able to host their clients in a "trusted" hub environment. A Bandwidth Barn focus group respondent praised the hub as "a professional-looking space to take clients", and in the words of one respondent (BBK1, 2017):

[...] people trust me more, because they believe I will give them a good service. They will say, "I can't give this guy business, because he doesn't have [an] office, he doesn't have a desk". [And] three years, five years from now, I would like to have a private room, not an open space.

One area where respondents pointed to a need for some improvement was in mentoring. Respondent T5 said there is a "lack of [the] right type of tech mentors that realise the difference between good tech and smoke and mirrors." According to one of the Bandwidth Barn Khayelitsha focus group respondents, it "would be more helpful if a mentor was appointed to do follow-up after training. Most times it's like you [are] on your own, you just swim on your own." There was a general view among users of the three hubs that, in addition to more regular mentoring, there is a need for more workshops on growing a business - and "not just the basic stuff", as one respondent put it, while acknowledging that this would have resource and cost implications. 
There was criticism, among respondents, of government support programmes being delivered through hubs. Respondent W17.2 argued that governmental enterprise development programmes tended to be poorly designed and bureaucratic, while another respondent argued that government support measures were unreliable. In the words of one of the Bandwidth Barn Khayelitsha focus group respondents:

As start-ups in our townships, we are struggling to access funding, more especially from [the] government side. When they [government representatives] present at imbizos [meetings], you feel you qualify, but when you get there, there are many [types of] red tape, and, by the time you comply, they tell you the budget is finished. Age is also counting. We can't get funding, because we are over the age. But also the youth can't get funding. [There are] lots of boundaries that you can't cross.

The tech hub management respondents spoke of a key dimension of their hubs being the fostering of synergies with potential future business partners. Hub manager respondents also reflected on the significant challenges associated with providing the necessary support to individuals and start-ups using the hub premises and services. In the words of respondent W17.4, knowledge creation for high-impact end-results requires a "high touch" approach to member engagement, i.e., "regular coffees and updates to know the customer" (respondent W17.4). According to one tech hub manager respondent, a hub is ideally able to apply the principle of "one size doesn't fit all", spending time with each start-up in order to understand the start-up's business, to offer advice, and to mentor. But the start-ups tend to need many hours of advice, particularly those coming from challenging socio-economic settings. Intensive individualised support for each start-up is typically not sustainable for a hub, given that a mentor resource may cost ZAR500 [USD30.89] per hour, or ZAR5,000 [USD308.91] per month—a cost higher than the hub's monthly membership fee.

According to a Tshimologong hub management respondent, many tech start-ups do not have the foundational knowledge or technical ability to use the full range of digital innovation tools (e.g., IoT tools, block chain tools) to create novel solutions, and they tend to get stuck at the ideas stage of knowledge creation (respondent T2). According to this respondent, while it may be tempting for hub management to seek to solve all problems, it is more realistic to strike a balance between, on the one hand, the hub providing support and solutions, and, on the other hand, the hub requiring tech start-ups to go out externally to find external avenues for support and solutions. But realism can be fraught: it tends to be very challenging for tech start-ups, on their own, to find external learning resources, generate the necessary contacts, and navigate the complex worlds of business and government. These challenges can easily lead to a mismatch of expectations between tech start-ups and hub management. 
Respondent T1 said that at Tshimologong, process matters are continually being reviewed, reset, and advanced, based on evolving insights gained by hub management and by its start-ups. At the time of the research, Tshimologong's emerging process (stated in broad terms) was to review the business concept proposed by each tech start-up, consider the technical viability of the idea, assess whether the tech start-up's team had the capacity to deliver, and understand the potential speed to get to market. Parameters and criteria for assessment in the pre-incubation stage included the tech start-up being required to: (1) create a business model identifying the target audience, stakeholders and resource requirements; (2) conduct some level of product-oriented research; (3) make a pitch; and (4) demonstrate progress. The hub had found that following these steps allowed incubatees to optimally unlock the opportunities provided by working with the broader community management team, which was able to focus on supporting the logistical aspects of getting the product to market (respondent T1).

One specific programme being delivered by Tshimologong at the time of the research was a cohort programme, with 20 start-ups per cohort, in which the cohorts worked through a 13-week programme that included orientation elements such as creating a business model canvas (a popular approach in the incubator world). Not all participants in the cohort moved at the same pace, meaning that, in the words of respondent T2, the approach was "great for management, but not for participants". After completion of the 13 intensive weeks, limited mentoring continued on a once-weekly basis for a maximum period of one more year. According to respondent T5, the challenge for start-ups in the cohorts was "coming with a question and leaving with an actual development".

Tshimologong also had, at the time of the research, a dedicated acceleration programme, for those who already had a business that was earning revenue and needed tailored support measures, such as a consultant support on intellectual property (IP) management or on tax matters. According to respondent T3, a participant in the programme:

The accelerator programme $[\ldots]$ was presented to us [as], if we put in the work and we meet our milestones, then we get access to investors. So it's an incentive for me to do my best work. Hence we decided to [...] concentrate on creating a product that people will be crazy about when we release it [...]. Here the thoughts are correct, the moulding of businesses [is] done the right way.

At time of the research, additional parameters were being put in place at Tshimologong for the accelerator stage. Explicit, written guidelines for expectations at each level of development were being designed by the business unit responsible for monitoring and evaluating the progress of community members (respondent T1). The 
goal was for the Tshimologong enterprises who were receiving acceleration support to have their activities and progress measured in terms of formal guidelines and criteria, while at the same time still allowing them the flexibility required to engage in innovation.

\section{Hub provision of networking opportunities}

Another core theme in the data is that of bub provision of networking opportunities, with the networks in question being both within the hubs and beyond in the hubs' greater ecosystems, and with the networks being grounded in the sharing of knowledge, of innovation, and of business opportunities. External networking opportunities are all specifically relevant to the start-up acceleration phase. This points to the specific importance of intangible knowledge resources as a key component of a desirable tech hub ecosystem.

Respondents spoke of the benefits of interaction and mutual support among individuals and entities within the tech hub, i.e., among developers, entrepreneurs, startups, and small enterprises. According to respondent W17.3, the conversations made possible by the tech hub are not about the passive intake of information, but rather they are seeds for practical approaches to creativity and production: "It's not merely theory." Respondent T5 from one of the Tshimologong start-ups said that their start-up is completely self-sufficient, and thus their key interest in being part of the hub is networking within a sharing community:

[...] the people and the networks you make with other people like yourself [...] [It] generates interest, gets like-minded people together. That's where real progress starts happening. By us being in close proximity, we can help each other out, due to our different expertise.

Respondent W17.1 spoke of the importance of hub provision of high-quality access to business and knowledge networks. Other respondents spoke of: the benefits experienced through business introductions enabled by the "high traffic" at the hub, the heightened opportunity for networking due to the presence of many diverse community members, and the hub providing a "centre of support in a faulty ecosystem" and "aggregation in the ecosystem" (BBK and W17 respondents). At the Tshimologong hub, key networking events are its hackathons, workshops, pitch sessions, and the annual Wits Fak'ugesi African digital creativity festival. In the words of Bandwidth Barn Khayelitsha respondent BBK5, who has attended the Wits Fak'ugesi festival at Tshimologong:

Last year September I attended the Fak'ugesi Festival, Jo'burg for the first time $[\ldots]$ the vibe, the culture, the activity $[. .$.$] we were playing games,$ people were sharing their stories, how they are creating their apps. I made friends. I met a lady doing an Instagram exhibition. We were building 
games, we were coding and I showed my own creative skills. I was with the Amaze team, programming. That's when I started to realise that I could create apps and websites, so such organisations are really helpful.

However, respondent T5 at Tshimologong said the hub needs to be do a better job of linking its hosted enterprises with outside stakeholders. The respondent gave the example of an event at the hub, to which external stakeholders were invited, which "did not feature any of the local people, or use any of the local people. [...] 50 people in the precinct and not one of them is showcased."

At Workshop 17, knowledge generation and networking are driven to a great extent by its events calendar. The calendar includes networking events to enable start-ups to engage with each other, and events at which industry leaders, academia, corporates, and enterprises showcase their knowledge and seek to build understanding. Workshop 17 is also active in facilitating introductions for funding, and it keeps a funding register (respondent W17.2). According to respondent W17.3, networking, both formal and informal, is regarded by Workshop 17 participants as a mode of creation, and a necessity for creation - and, accordingly, hub community members invest time and energy in going to the hub's events, thus helping feed the community's networking, meet-up, and developer ethos.

According to respondent BBK2 at Bandwidth Barn Khayelitsha: "This space plays a role through events and providing the networking. Most $[\ldots]$ young people are starting businesses and they fail. So this space is important to the long-term success of small business in Khayelitsha." Key to the Bandwidth Barn's provision of networking are its relationships with local partners. Its partners include local tour guides offering "the Khayelitsha experience", corporate partners Airbnb and Telkom, and government partner the Western Cape Department of Economic Development and Tourism.

\section{Hub provision of opportunities for collaboration}

A third core theme in the data is bub provision of opportunities for collaboration, with the collaboration being grounded in sharing (of information, knowledge, and experience), and in peer-to-peer learning and skills development modalities. At Bandwidth Barn Khayelitsha, the hosted start-ups, both non-profit and for-profit, "circulate business among ourselves" (BFG respondent), with some of the hub's enterprises providing, for example, advertising and facilitation services to other enterprises at the hub. This data points to the emergence and presence of the values of collaborative learning and knowledge sharing in pursuit of innovation outputs. 
According to respondent BBK2:

You learn some other ideas from the other people, not your own way of doing things $[\ldots]$ sometimes you meet other business owners here who do auditing and other guys are doing tax returns so they help you, they do the online tax filing [...] [and learning] how to use your cellphone for your business, some things I didn't even know, [like how to] speak to a person via Skype.

Success is very much linked to knowledge-sharing [...] I can do more, I am getting more business than before [...] more clients, more income, more networks. Online includes email, internet payments for staff, internet banking, phone people using Skype. Most young people use technology using their phones. We have pamphlets and posters at the malls and they call and email back, [and we conduct] online interviews using Skype. People email their $\mathrm{CV}$ s straight to you, people email requesting interviews $[\ldots]$ Easy when you work with the bank. Today I was busy investing money with the bank online.

Another Bandwidth Barn respondent (BBK5) spoke of the values associated with enterprises "trading" design skills for income, in order to generate mutual benefit:

I'm a painter and a designer. [...] I wanted to trade the skills to make other businesses successful [...] because I saw a gap where small businesses are existing in the market without an image and a corporate identity. In a digital world, every business is online but [some businesses] are not in that world, so I wanted to create digital marketing and branding for small businesses in Khayelitsha and in South Africa, from start-up business to existing businesses, and make that service available online through direct marketing and driving traffic to my website.

This creative design and digital marketing, this is innovation. [...] I want to teach people how to do creative design and teach entrepreneurs the importance of design for their business, for businesses who do not have a great awareness [of] tech-enabled branding, mainly start-ups, especially the design using digital software and interacting through digital spaces.

\section{Tshimologong respondent T3 spoke of the importance of peer-to-peer knowl- edge creation:}

Knowledge creation amongst our peers is predominantly through observation and engaging the market, testing your assumptions. Ninety per cent of the time your assumptions are incorrect and that's at the heart of knowledge creation in the start-up context $[\ldots]$ can't be too theoretical $[\ldots]$ have to put it into practice [...]. 
At Workshop 17, respondent W17.1 highlighted the power of everyday conversation, and told the story of

[...] two start-ups talking about different technologies and challenges in collaboration [...] [saying things like] "Sounds like this is your challenge [...] I've used this alternative tech [...] would it be useful to you?" Six months later this tech was core in their delivery, so a casual conversation led to formalisation in their operation.

Another anecdote told was one in which hearing about a failure from peers at the hub led developers along a different route, saving them significant time and money. This respondent spoke of the ideal where the developers and entrepreneurs at the hub are all mentors to each other. Respondent W17.4 spoke of the importance of a collaborative environment in building the resilience that start-ups need in order "to work through the hard times":

[There is] greater resilience in a tech hub than outside a tech hub, because the success of those around you drives you to be successful [...]. Being resilient is often not [about] being by yourself and pushing by yourself [...]. [You] can be cornered in your own organisation. But when you're surrounded by 93 companies and sharing success and failure, [this] aids resilience. Fail, share, have a coffee, get some perspective. [That] creates resilience.

It was also felt that collaboration was an important contributor to building relationships-relationships, between enterprises, that are built around trust, value creation, and mutual benefit through reaching a given outcome, or through building a particular product, "and sometimes [building] sales opportunities" (respondent W17.5). It was said that relationships built up over time create credibility in terms of ability to deliver and ability to perform. For start-ups, such relationships are not only important with their peers but also with hub community leaders and, often more importantly, hub middle management, with whom the start-ups interact frequently.

However, at the same time, respondents identified elements needing improvement in hubs' delivery of opportunities for collaboration. Respondents at both Bandwidth Barn Khayelitsha and Workshop 17 spoke of the need for their respective hubs to be based to a greater extent on creating opportunity to experiment, on being places where "things [are] happening on the floor"-with greater peer-to-peer exchange, greater levels of advising and understanding among start-ups, more collaborating through business referrals, and more pulling of other tenants into each other's teams (respondent BBK6; multiple W17 respondents). Respondent T5 at Tshimologong was concerned that there is "not sufficient acknowledgement" of the people and 
projects that are "instrumental in the production" that occurs at the hub: "The precinct talks about the community, but gives themselves kudos, [and] not the businesses concerned."

Addressing the dynamics of relations between hub users, respondent T3 stated that "a lot of the attempts to collaborate and create value [i.e., benefits or advantages] for our peers left many people feeling that they got the short end of the stick." Respondent T3 spoke of the importance of

[...] building the culture of creating things together and, if things didn't go well, building the culture of reconciling ourselves to that. [This is] the value of failing forward. But honesty is in short supply. On integrity, we fall short. At this stage of the evolution of the ecosystem, which is still in its infancy, [integrity] needs to be curated into the DNA of the ecosystem [so as to create] a more inclusive innovation space. [...] Here it's about us, us, us the value [i.e., benefit or advantage] of the community not the individual. [...] For Africa, the community is more important than the individual. Yes, there will be things that go seriously wrong, so how do you come out of that and still collaborate rather than walk away?

Respondent T3 stated that collaboration can be undermined when enterprises perceive one another as competitors:

[...] developers working in Java and PHP should be collaborating, but don't, because they think they're going after the same client - but they're not. They could be creating an integrated or collaborative offering [...] [saying to each other] "I can't do it alone, let's go and present together".

\section{Hub and start-up approaches to knowledge governance}

A fourth core theme found to be present in the data is approaches to knowledge governance by hubs and by their hosted enterprises. The concept of knowledge governance refers, in this context, to approaches to protecting and/or sharing innovations, including making use of intellectual property tools. Respondents T1 and W17.1 said IP ownership is a not a priority for them, as they want to focus their efforts on generating innovations. As one of these respondents said, "[we are] not necessarily interested in owning the IP, because we believe we can always come up with new IP". This cluster of data relates to the early stage of innovation output, to the intellectual property generation that the actors and institutions seek as a common purpose in the process of value creation. The nature of intellectual property rights, what can and 
cannot, or should and should not be protected, and how and when to protect IP were not always clear to the respondents in the tech hubs studied. However, tech start-ups lean towards generating IP that is then freely available to share and leverage.

The prevailing logic among many of the respondents engaged in software development is that, in the software realm, it is important to continually build from scratch, partly because this creates the knowledge foundations that give the particular developer the advantage to continually build the next thing. At Workshop 17, respondent W17.5 stated that the open ethos in the digital innovation environment, where a great deal of development occurs on open platforms, dilutes the "need and desire" to keep IP closed:

Many companies are desensitised to the core IP [...]. They are willing to share with less emotion, because the tech industry is so quick in terms of innovation and how quickly things move. What's relevant today may not be relevant tomorrow. [The] rate of change is key to knowledge-sharing.

Respondent W17.5 explained that while the rapid rate of change "may be a barrier to entry for some", it can be overcome through "more familiarity in terms of [being] first to market and, in our instance certainly, relationships". For respondent W17.3, IP is not something that requires a focus on protection, as their firm is more concerned with the services it can provide and sell based on the IP it has generated.

However, at the same time, some respondents, such as respondent T3 at Tshimologong, spoke of the importance of IP ownership, with respondent T3 saying that one role of the Tshimologong hub is to provide advice for start-ups on IP rights and IP law. "If I write code, the IP is mine", respondent T3 stated, adding that several start-ups at the hub were hoping that Tshimologong would help them in protecting their IP, due to their fear that an investor might seek access to the IP as part of an investment. Respondent T3 spoke of the often limited awareness of the dynamics of IP protection, with the start-ups in question being unclear about how to manage this part of investor relationship-building:

the start-up does not know how to package the knowledge in terms of IP. [...] When you are talking to investors, [you] don't know what to keep and what to divulge, what to protect and how to leverage the IP, hence the usefulness of being at the university. That's one core thing that should be given to us at the end of the 12 weeks [of the accelerator training programme]: [knowledge about] how you create trademarks, [how] to open it up to the market so that people play around with it. We think about IP incorrectly as entrepreneurs, [with] fear, [which hinders] entrepreneurial success. 
Respondent T2, functioning in a community management role at Tshimologong, stated that the hub does not seek any share of IP rights that may emerge from innovations generated by start-ups at the hub.

\begin{abstract}
If there is any sniff of Wits [University] owning IP as a condition for using the space, they [tech start-ups] will not come here. So they pay a membership fee; we give everyone a vanilla-flavoured package of support; there's no Wits IP in the package and they own $100 \%$ IP and equity in their company. If they want to work with a Wits academic to support one of the start-ups, we would fall under the national IP Act, but that hasn't happened yet.
\end{abstract}

The Wits IP policy specifies that the university owns IP created by employees, and thus it does not cover any of the Tshimologong hub participants, such as the start-up participants, who are not Wits employees.

\title{
Hub and start-up approaches to local appropriateness
}

The last core theme present in the data is approaches to local appropriateness, i.e., approaches to serving the needs of local innovators and the needs of local citizens and consumers. This cluster of data relates to the forms of value that were generated in the tech hubs studied.

The hub where these matters were found to be most complex is Bandwidth Barn Khayelitsha, which faces acute socio-economic challenges linked to its spatial and economic isolation within greater Cape Town. Khayelitsha is about 35 kilometres from downtown Cape Town and is poorly connected, by transport and other economic infrastructure, to local resources and markets. The impoverished conditions experienced by most of the households in the township make local appropriateness a great challenge for Bandwidth Barn Khayelitsha innovators seeking to serve local needs. Many Khayelitsha residents do not own a smartphone or, if they do own a smartphone, they often lack the ability to pay for large amounts of internet data usage. Also, local clients for Bandwidth Barn developers' services tend not to have large budgets at their disposal.

Due to local factors such as these, respondent BBK6's development team at the Bandwidth Barn has found itself "forced" to provide only basic web development and social media support services, in order to cater to local client needs-rather than making use of the team's higher-level skills in mobile app development, robotics, and artificial intelligence. In the words of respondent BBK6:

We want to get into that [higher-level development], but most of these things require a specific amount of funding. If clients cannot meet the cost requirements, then it can't be done. We have been doing some exploration, but it all came down to the fact that we need resources. 
According to respondent BBK4 at the Bandwidth Barn, a tech hub needs to be a space for increasing the levels of digital participation in its broader community:

A lot of the businesses operating here are tech-enabled, and other businesses operating here are starting to understand the shift to tech enablement, [as are the] local schools coming in [...]. The tech hub is a key component in shifting towards a tech-enabled Khayelitsha.

According to BBK respondents, Khayelitsha's economic and social isolation needs to be decreased, through the efforts of the local community working together with government, private-sector, and non-profit partners, in order for the tech hub to reach its full potential. The hub and the broader Khayelitsha community need to transition from being entities that are "being looked at" to entities that are understood to be partners with economic potential (respondents BBK4, BBK7). One of the challenges in building the tech hub community in Khayelitsha is that "most people start a business because they want to earn money, not because they've done a market analysis. However, members of the [tech hub] community need to [...] have a creative mindset $[\ldots]$ to be able to compete" (respondent BBK7).

For all three tech hubs studied, although there are marked differences across the socioeconomic contexts in which they operate, the imperative that innovations emerging from the hub are locally appropriate is, at each hub, a highly challenging one to meet. In the words of respondent T2 at Tshimologong, "people fall in love with their technology, and may be developing something not wanted by the target market. So [there needs to be an emphasis on] understanding your customer/market, not just loving the tech." Success, according to respondent T2, is about building sustainable businesses, and "not just about ticking the boxes of ideas, the business model [...]. Until [you are] operating in the world and creating revenue, you haven't achieved anything."

According to respondent T1 at Tshimologong, ideas for digital production and services need "to be disruptive in nature, or have high impact in one's community, [...] social impact, [serving as] an enabler that simplifies people's lives.” In the words of respondent $\mathrm{T} 3$ at Tshimologong:

One of our primary activities is research, [which] should be [the] practice for all businesses: research your market, would-be buyers, their psychology [...]. Any business should be a research-based business, underlying the development of digital products. For us, innovation is about: what are the real problems that people are not thinking about? [...] We use design thinking. We are not trained researchers, but we use the available tools within this tech hub to do our work. 


\section{Analysis: Innovation entanglement, scale, and sustainability}

Two cross-cutting themes present in much of the data from the interviews and the focus group discussion are (1) the quest, by the hubs and start-ups, for scale; and (2) the hubs' and start-ups' quest for sustainability. It must be noted that the terms "scale" and "sustainability" are, of course, open to varying interpretations. Furthermore, as outlined in the recent Scaling Innovation research report by the Open African Innovation Research network (Open AIR, 2020), sustainability is often a central feature of successful scaling. In this study, the conceptions of scaling and sustainability posited by the interviewees and focus group respondents are particularly present in the statements they provided on matters of:

- overcoming adversity and responding favourably to complexity in tech hub innovation ecosystems; and

- building multi-dimensional innovation ecosystems.

The five components of the entanglement conceptual framework outlined at the beginning of this article - namely actors, institutions, resources, values, and value-are represented in the data in respect of how start-ups (actors) and tech hubs (institutions) leverage infrastructure and tech-support services (resources), as well as collaborative learning and knowledge-sharing (values), to foster the creation of applications and platforms to meet demand (value). This enables the poorly resourced actors and institutions to manage the complexity of interacting in knowledge markets. This study thus contributes to an expanded exploration of the entanglement framework, notably the findings that tech start-up actors and tech hub institutions freely engage in entanglement dynamics; that key types of resources are both exogenous (tangible, specialised infrastructure and services for tech start-ups), and endogenous (intangible knowledge resources); that key values are collaborative learning and knowledge-sharing; and that output value is constituted by freely available IP, as well as locally appropriate software, content, and applications. This research expanded the initial framework of research entanglement, to create a means of understanding innovation entanglement in tech hubs.

Certain of the findings accord with the data on open innovation approaches in the relevant literature, but this article extends that knowledge through the theorisation of innovation entanglement behaviour. In particular, what is new to our understanding are the findings that (1) shaping or success factors present in highly resourced, highly structured innovation environments also emerge strongly in poorly resourced, embryonic tech hubs; and that (2) a key to sustainability and scalability, for both the start-ups and the tech hubs, is their mutual entanglement in the processes of accessing resources, building values systems, and creating value, irrespective of how fractured and non-linear these processes may be. With respect to mutual entanglement, the crucial point is that actors and institutions become involved in a heightened 
state of interaction with the competing ecosystem factors and the external entities, in "messy" ways, moving along paths that show some significant resistance, as they seek the optimal solutions under adverse circumstances. In other words, the actors and institutions often seek paths of significant resistance, rather than paths of least resistance.

\section{Overcoming adversity and responding favourably to complexity in tech hub innovation ecosystems}

The start-up actors studied have emerged from environments characterised by lack of easy access to institutions, to resources, to the private sector, and to markets. They also lack formal access to universities and university research sub-systems, and to publicly funded research entities. The start-up actors have been compelled to move into a particular kind of institutional setting, a tech hub, at which they have to attempt to create and co-create in the face of adverse conditions-conditions which do not disappear just because the actors are now based at a tech hub. Even when operating out of a hub, the start-up actors still do not have easy access to significant amounts of finance, investment, skills, and knowledge. Despite their resource constraints, tech hubs and their resident start-ups persist in their contribution to digital innovation at the small, local scale, with potential for contributing at the regional scale.

The particular form of innovation support looked at in this study, where start-ups are fostered by tech hubs, lacks the relative financial certainty and stability, and relatively predictable path to achieving scale and sustainability, found in innovation-support endeavours taking place in large private-sector entities, in some university entities, and in government-supported research and development (R\&D) entities-although of course it must be noted that digital innovation tends to be a medium- to high-risk endeavour in almost any conditions. Risk tends to be more effectively mitigated in business and government contexts-through engagement in multiple simultaneous initiatives and the ability to wait and see which ones pay off-while tech hubs, in the South African context at least, tend to lack (compared to the private and public sectors) the extensive human and financial resources necessary to create many parallel development initiatives.

The start-up entities accepted into a hub's incubation programmes, and/or making use of a hub's infrastructure and services, tend to be characterised by low and irregular income, and limited savings. Accordingly, some tech start-ups give up, while others manage to push through the adversity and stay on the path towards scaling and sustainability. Some tech start-ups grasp every opportunity to remain in whatever programme they are accepted into, while others drop out, or fail to take full advantage 
of a hub's services and opportunities. This raises the question as to the distinguishing features of those tech start-ups that are able to stay on the necessary path. According to respondent $\mathrm{T} 5$ :

\begin{abstract}
What defines the real techies [as opposed] to the people just trying to make money, [is that the techies] will push through regardless of the circumstances. Most people in the space will keep pushing through, even if they don't get the support they need, even if they don't get the business models. That kind of mentality is going to grow those people [...]. The fact that we believe in the tech that we use [means that this type of business] will be a viable business [...]. [We are] spending a lot of resources at the early stage of the technology, getting limited output from the resource input, but we know that this will change [...]. [It] has to be sustainable, but even when things are tight, we love what we [are] doing and we keep pushing on.
\end{abstract}

Volunteering and "hustling" by start-ups are noted as being important to making them, and the tech hubs that they are part of, successful. Hustling is understood as grasping every opportunity, and constantly looking for, and taking on, temporary projects, particularly ones that create short-term income generation opportunities for start-ups and their teams, one example being events management for local sports events. Respondent BBK1 summarised this approach as follows: "one space, two hustlers, and 500 people getting an income".

According to respondent W17.1 at Workshop 17, a key dimension of adversity is uncertainty, and hence, according to this respondent, incubated start-up enterprises may sometimes, in the face of this uncertainty, need or specifically choose to take on "too much", as this may create small growth opportunities in the short term, with sustainable business or employment opportunities only arising in the longer term. In a context such as South Africa, with its huge income disparities and its history of deliberate under-development of areas inhabited by black South Africans, another element of the adversity and complexity is the negative assumptions often made about small-scale black innovators. In the words of respondent BBK6 at the Bandwidth Barn:

[innovative] ideas are expected to come from a certain organisation/race/ company, in terms of size, so when a small, black company comes up with something disruptive, it's not really trusted. There's a question of legitimacy $[\ldots]$.

Another element of adversity for the start-ups on the path to scaling and sustainability is the need to take an innovation to market, so as to monetise it. Creating the bridge into the corporate market, and speaking the corporate language, requires more than just business models. It requires learning how to actually be in business. 
In the words of respondent W17.1, “[...] what we've learned from the market [is that] being a small company in a mature market is extremely tough". According to respondent W17.5, participation in the market also requires learning how to operate successfully in the face of global economic downturns (a statement that has been made highly prescient by the subsequent emergence of the COVID-19 pandemic).

With respect to the tech hubs, and the scaling of their offerings and building of their sustainability, the data analysis indicates that external funding can be a double-edged sword. While it can help a great deal, at the same time, it potentially leads to over-dependence on money that arrives (and may abruptly stop arriving), at the whim of a donor. According to respondent T2 at Tshimologong, resources acquired not through donor-recipient relationships but rather through operational partnerships with industry, in which mutual self-interest can be established and both parties feel they gain from the arrangement, have much greater potential stability. Ultimately, tech hubs need to foster a multiplicity of resource streams.

Accordingly, the activities of tech hubs and their start-ups must be aimed towards deep engagement in the broader digital innovation ecosystems beyond the hubs, in order to effectively overcome adversity and benefit from complexity. This deep engagement needs to be with potential future customers, where the strength of future relationships and networks is uncertain; with knowledge brokers and specialists; with IP lawyers and advisors; and with the consumer markets that will determine and influence local appropriateness and therefore the value of the applications and services. Such engagements tend to be highly demanding of time and available knowledge, and tend to greatly stretch tactical organisational capabilities-yet they are too attractive to avoid. The result is a high degree of entanglement, where an individual start-up may be engaging with many possible collaborators and future clients in parallel, in order to counterbalance the absence of even small-scale investment capital.

\section{Building multi-dimensional innovation ecosystems}

According to several respondents, when start-ups begin to mature and pursue scale and sustainability, they want, and need, to be fully embedded in a larger innovation ecosystem. A key feature of scaling is increased access to local, regional, or global marketplaces - particularly for the tech hubs that need to scale to push forward access to markets, while individual start-ups will have limited potential for such engagement. Extensive reach and insight into potential future markets and specialisations is an emerging area of focus for tech hubs, as they are more able than individual start-ups to negotiate this level of entanglement. One key feature of engaging with markets, according to respondents at all three hubs, is creation of innovation specialisations - through, for example, a focus on gaming and gamification at one hub, and a focus on fintech or edtech at another. The necessary complex matching processes require tech hub facilitators to have skill sets that can make such specialisations work. 
In the data from the tech hub interviews, it is clear that greater attention is needed to optimise the roles of all potential partners in knowledge generation processes: the roles of the start-ups, the hubs, and, for example, university academics and private-sector industry partners. Respondent $\mathrm{T} 1$ spoke of the great potential, at Tshimologong, for greater integration between the Wits University academic community and the digital tech community at the precinct; greater integration between the university's Engineering Faculty and the tech hub so as to enable the tech community to benefit from shared access to equipment; and greater knowledge-sharing between the hub's enterprises and academics working in the biosciences. Respondent T3 cited the significant potential for innovation that could be fostered if Tshimologong start-ups were to have access to university-based scientists such as entomologists (relevant to designing applications to manage pests in fruit or nut orchards), to academics in mining or health sciences (relevant to designing digital mining or digital health applications), and to academics working on IP law (relevant to the design of industry-start-up contracts). Regardless of whether or not a tech hub is based at a tertiary institution, access to and integration between the tech hub and a university or a technical and vocational college can be mutually beneficial to both entities, as each learns progressively from the other.

These findings, on tech start-ups' and tech hubs' pursuit of scaling and sustainability through leveraging prevalent competing ecosystem factors and building numerous complex relationships with external entities in an innovation ecosystem, link to findings from my earlier research (Abrahams, 2016). In that earlier study, I was able to identify the importance of entanglement between a heterogeneous group of non-university-based and university-based research-innovation actors. In the context of this current study, innovation entanglement helps elucidate the dynamics present in relations between hubs, hub start-ups, and external entities in their innovation ecosystems (e.g., universities, private-sector entities, government entities, donors, and non-profit organisations). There is evidence that the hubs and start-ups work through adversity and complexity, and increase their chances of succeeding, through entanglements with large entities, such as universities, private-sector actors, branches of government, or development donors, and through webs of entangled relationships between tech start-ups, between start-ups and hubs, and between hubs.

\section{Applying the innovation entanglement framework to tech hubs}

Based on the findings of both the earlier research (Abrahams, 2016) and this more recent study, I conclude that, for tech hubs, their start-ups, and the external entities with which they interact (whether universities, private-sector entities, branches of government, donors or non-profits) - when engaged in innovation as a form of communitarian behaviour and contending with competing factors grounded in resources, values, and value - the entanglement dynamic plays out in two main ways. 
A first entanglement modality is one spearheaded by the large, formalised entities in the communitarian innovation ecosystem, entities that will tend to be oriented towards bureaucratic imperatives. The downside of this kind of entanglement for small-scale innovation actors and institutions (i.e., start-ups and tech hubs) is that large bureaucratic formations tend not to have a feel for the DNA of communitarian values as understood by smaller-scale actors and institutions. Large, formal entities, e.g., universities, governments, sizeable private-sector entities, and sizeable donors or non-profits, will tend to assert, or reassert, rigid rule-driven governance and management frameworks. A university, for example, will tend to be guided by highly organised, and highly rationalised, memes for organising R\&D and innovation. It will generally have standardised functions for funding and reporting. It will generally require conformity to rigid frameworks for performance that are set by the university and must be followed, even where greater flexibility may be required in terms of what constitutes success, failure, or resilience. University-based R\&D, even in the 21st century, tends to be a highly structured domain.

A second entanglement modality, which is more amenable to the inherent ethos of a tech hub and its start-ups, is one in which the ecosystem's "soft science" innovation elements are prevalent and strongly fostered. This would produce an entanglement ethos characterised by flexibility, rather than by the relative rigidity of the "hard science" innovation pursued by large, formalised entities. It is likely that the ideal for tech hubs and their start-ups is the co-existence of these two entanglement modalities, such that a tech hub and its start-ups can participate in, and benefit from, both types of innovation entanglement.

\section{References}

Abrahams, L. (2016). Trends, tropes and positioning in the university research sub-system in emerging knowledge economies: A theory of research entanglement. $\mathrm{PhD}$ thesis, University of the Witwatersrand, Johannesburg.

Adler, P., Florida, R., King, K., \& Mellander, C. (2019). The city and high-tech startups: The spatial organization of Schumpeterian entrepreneurship. Cities, 87, 121-130. https://doi.org/10.1016/j.cities.2018.12.013

Atiase, V. Y., Kolade, O., \& Liedong, T. A. (2020). The emergence and strategy of tech hubs in Africa: Implications for knowledge production and value creation. Technological Forecasting and Social Change, 161,1-13. https://doi.org/10.1016/j.techfore.2020.120307

Balboni, B., Bortoluzzi, G., Pugliese, R., \& Tracogna, A. (2019). Business model evolution, contextual ambidexterity and the growth performance of high-tech start-ups. Journal of Business Research, 99, 115-124. https://doi.org/10.1016/j.jbusres.2019.02.029

Banai, R. (2020). Pandemic and the planning of resilient cities and regions. Cities, 106, 1-6. https://doi.org/10.1016/j.cities.2020.102929

Bandwidth Barn Khayelitsha. (n.d.). [Website]. https://www.citi.org.za/spaces/bandwidth-barn-khayelitsha/ Beyond Our Borders. (2017). The Khayelitsha Project. https://beyondourborders.net/the-khayelitsha-project/ 
Comins, N. R., \& Kraemer-Mbula, E. (2016). Innovation hubs in Southern Africa. In O. Adesida, G. Karuri-Sebina, \& J. Resende-Santos (Eds.), Innovation Africa: Emerging hubs of excellence (pp. 37-98). Emerald.

https://doi.org/10.1108/978-1-78560-311-220151003

De, R., Pandey, N., \& Pal, A. (2020). Impact of digital surge during Covid-19 pandemic: A viewpoint on research and practice. International Journal of Information Management, 55, 1-5. https://doi.org/10.1016/j.ijinfomgt.2020.102171

De Beer, J., Millar, P., Mwangi, J., Nzomo, V., \& Rutenberg, I. (2017). A framework for assessing technology hubs in Africa. Journal of Intellectual Property and Entertainment Law, 6(2), 237-277. https://www.researchgate.net/publication/318710029 A Framework_for_Assessing_Technology_Hubs_in_Africa

Desta, T. (2018). ICT innovations, entrepreneurship and hubs in East Africa: The case of Ethiopia. African Journal of Science, Technology, Innovation and Development, 10(6), 655-664. https://doi.org/10.1080/20421338.2018.1473064

ElHoussamy, N., Weheba, N., \& Rizk, N. (2020). Power relations, innovation, scaling and knowledge governance at three Egyptian tech hubs: An initial exploration. Open AIR Working Paper 21. Open African Innovation Research (Open AIR) network. https://openair.africa/power-relations-innovation-scaling-and-knowledge-governance-at-three-egyptian-tech-hubs-an-initial-exploration/

Fak'ugesi (n.d.). [Website]. https://fakugesi.co.za/

Friederici, N. (2019). Innovation hubs in Africa: What do they really do for digital entrepreneurs? In N. D. Taura, E. Bolat, \& N. O. Madichie (Eds.), Digital entrepreneurship in Sub-Saharan Africa: Challenges, opportunities and prospects (pp. 9-28). Palgrave Macmillan. https://doi.org/10.1007/978-3-030-04924-9 2

Giuliani, D., \& Ajadi, S. (2019, July 10). 618 active tech hubs: The backbone of Africa's tech ecosystem. [Blog post]. GSMA Ecosystem Accelerator. https://www.gsma.com/ mobilefordevelopment/blog/618-active-tech-hubs-the-backbone-of-africas-techecosystem/

Giuliani, D., With, L. H., Ekeledo, A., \& Isedowo, T. (2019). Building a conducive setting for innovators to thrive: A qualitative and quantitative study of a hundred hubs across Africa. AfriLabs and Briter Bridges. https://briterbridges.com/briterafrilabs2019

Gregory, J., \& Rogerson, J. (2019). Studentification and commodification of student lifestyle in Braamfontein, Johannesburg. Urbani izziv, 30, 178-193. https://doi.org/10.5379/urbani-izziv-en-2019-30-supplement-012

Holst, A. (2020, March 2). African enterprises: Major cloud providers 2018. Statista. https://www.statista.com/statistics/878804/kenya-nigeria-south-africa-enterprise-key-cloud-providers/

Huwart, J. (2015). Growth, challenges and promises of coworking in Africa. [Conference presentation]. Coworking Africa conference, 23-24 July, Cape Town. https://www. slideshare.net/Jeanyveshuwart/2-keynote-coworking-africa-2015-jy

Jiménez, A., \& Zheng, Y. (2017). Tech hubs, innovation and development. Information Technology for Development. 24(1), 95-118.

https://doi.org/10.1080/02681102.2017.1335282 
Kelly, T., \& Firestone, R. (2016). How tech hubs are helping to drive economic growth in Africa. World Development Report 2016 Background Paper. World Bank. https://openknowledge.worldbank.org/handle/10986/23645

Lee, S. M., \& Trimi, S. (forthcoming 2021). Convergence innovation in the digital age and in the COVID-19 pandemic crisis. Journal of Business Research, 123, 14-22. https://doi.org/10.1016/j.jbusres.2020.09.041

Littlewood, D., \& Kiyumbu, W. (2018). "Hub” organisations in Kenya: What are they? What do they do? And what is their potential? Technological Forecasting and Social Change, 131, 276-285. https://doi.org/10.1016/j.techfore.2017.09.031

Nzomo, V., Mwangi, J., Matu-Mureithi, L., Muchiri, C. W., \& Rutenberg, I. (2020). Modes of innovation and enterprise development by Nairobis mobile tech start-ups. Open AIR Working Paper 22. Open African Innovation Research (Open AIR) network.

Open African Innovation Research (Open AIR). (2020). Scaling innovation: How open collaborative models help scale Africa's knowledge-based enterprises. https://openair.africa/scaling-innovation-how-open-collaborative-models-help-scale-africas-knowledge-based-enterprises/

Trangoš, G. (2015, June 2). Photos: An emerging Joburg neighborhood challenges Cape Town's fickle hipster culture. Quartz Africa. https://qz.com/416132/photos-anemerging-joburg-neighborhood-challenges-cape-towns-fickle-hipster-culture/

Tshimologong Digital Innovation Precinct. (2020). Membership scheme. https://tshimologong.joburg/community/membership-scheme/

Tshimologong Digital Innovation Precinct. (n.d.). [Website]. https://tshimologong.joburg/

Van der Aalst, W., Hinz, O., \& Weinhardt, C. (2019). Big digital platforms: Growth, impact and challenges. Business E Information Systems Engineering, 61(6), 645-648. https:// doi.org/10.1007/s12599-019-00618-y

V\&A Waterfront. (2020). Our history. https://www.waterfront.co.za/the-va/the-company/ our-history/

Workshop 17. (2020). Individual solutions, rates and inclusions. https://workshop17.co.za/ individual

World Bank. (2016). World development report 2016: Digital dividends. https://doi.org/10.1596/978-1-4648-0671-1

Zwegers, A., \& Sassen, A-M. (2015, October 2). Digital innovation hubs at ICT 2015 [Blog post]. European Commission. https://ec.europa.eu/digital-single-market/en/blog/ digital-innovation-hubs-ict-2015

\section{Research respondents}

At Bandwidth Barn Khayelitsha, Cape Town, interviewed in 2017

Respondent BBK1.

Respondent BBK2.

Respondent BBK3.

Respondent BBK4.

Respondent BBK5.

Respondent BBK6.

Respondent BBK7. 
At Workshop 17, Cape Town, interviewed in 2017

Respondent W17.1.

Respondent W17.2.

Respondent W17.3.

Respondent W17.4.

Respondent W17.5.

At Tshimologong Digital Innovation Precinct, Johannesburg, interviewed in 2017

Respondent T1.

Respondent T2.

Respondent T3.

Respondent T4.

Respondent T5.

Bandwidth Barn Khayelitsha focus group, Cape Town, conducted in 2017

$\mathrm{BFG}$ respondents.

\section{Appendix A: Protocol for Semi-Structured Interviews}

Broad designation and institution of key informant (for analysis purposes only):

\section{Date of interview:}

Please note that these are guiding questions. The researcher is interested in noting and understanding the histories, nature and characteristics of high-tech hubs and those factors that foster their success, in particular with respect to knowledge governance.

\section{Metrics}

(i) Please mention or refer us to some of the key metrics that reflect the status and level of advancement of this high-tech hub, including

- metrics for innovation input and output

- metrics of innovation value produced

- any other relevant metrics

\section{Modes of knowledge creation and knowledge governance}

(ii) What are the prevailing modes of knowledge creation at the tech hub and the related governance mechanisms?

(iii) In your view, what is it that academics, innovators and managers do that tends to lead to success in the innovation project, or to lead to failure in the innovation project?

(iv) In your view, what is it that academics, innovators and managers do that tends to lead to success in the long term innovation venture, or to lead to failure of the high-tech hub?

\section{Understanding the complex context for innovation practices}

(v) How do the complex challenges of innovation practice on a short-term (one year) and a long-term (3 to 5 year) basis affect your knowledge creation and knowledge governance behaviours?

(vi) How does government and institutional policy, law and regulation, in particular, IP law and open IP approaches affect your knowledge creation and knowledge governance behaviours? 
(vii) How do tech transfer offices, advisors, financing and other support measures enable or present barriers to your innovation projects and to high-tech hub development?

\section{High-tech hub evolution}

(viii) Briefly explain this high-tech hub's evolution in terms of any of the following:

- innovation and knowledge production

- collaborative innovation

- appropriation of intellectual property (IP)

- the role and contributions of innovation actors, innovation-oriented institutions and innovation resources

- the nature and importance of innovation-oriented values

- the innovation value produced

\section{Appendix B: Focus Group Guide}

Broad designation and institution of key informants (for analysis purposes only):

\section{Date of focus group event:}

Note to focus group: Please note that these are guiding questions. The researcher is interested in noting and understanding the histories, nature and characteristics of high-tech hubs and those factors that foster their success, in particular with respect to knowledge governance. This particular set of questions is aimed at understanding your collective view of the collaborative innovation experience.

\section{Metrics}

(i) How would you measure the success of the innovation activities that you engage in here at the high-tech hub?

\section{Modes of knowledge creation and knowledge governance}

(ii) Please explain how you produce knowledge in this collaborative working environment. [For example, why is it better to engage in collaborative innovation than to work alone?]

(iii) How is the intellectual property you create owned and released or used for commercial or social or public benefit?

(iv) How do you earn income or other value from the intellectual property you create?

\section{Understanding the complex context for innovation practices}

(v) Please briefly explain some of the major challenges you face in this form of collaborative innovation.

(vi) How do you address or resolve these challenges?

(vii) What, in your view, are the strengths and weaknesses of how innovation is governed/ managed in this high-tech hub? [For example, decision making, management, leadership, government policy or law or regulation, tech advisors, financing, any other]

\section{High-tech hub evolution}

(viii) What, in your view, are the overall strengths and weaknesses of the high-tech hub approach to innovation? 